\title{
Orange-Fleshed Sweet Potato (Ipomoea batatas L (Lam)) Composite Spaghetti has Good Consumer Acceptability and a Significant Source of Dietary Vitamin A
}

\author{
Richard Atinpoore Atuna $^{1 *}$, Nyarkoa Deborah ${ }^{2}$ and Francis Kweku Amagloh ${ }^{1}$ \\ ${ }^{1}$ Department of Food Science \& Technology, University for Development Studies, Tamale, Ghana \\ ${ }^{2}$ Department of Family \& Consumer Sciences, University for Development Studies, Tamale, Ghana \\ Correspondence should be addressed to Richard Atinpoore Atuna, ratuna@uds.edu.gh
}

Received: February 25, 2019; Accepted: March 20, 2020; Published: March 27, 2020

\begin{abstract}
Objective

In this study, orange-fleshed sweet potato (OFSP) puree was substituted with wheat flour (48:52\%) in the production of spaghetti, herein denoted VitAspag and compared with three existing whole wheat brands (Local, Oba and Spaghetti).
\end{abstract}

\section{Methods}

Hundred untrained panel list evaluated the colour, taste, stickiness, firmness and overall acceptability using a 5-point hedonic scale. The proximate and $\beta$-carotene content of VitAspag was carried out using standard methods and compared with the most preferred existing brand, Spaghetti.

\section{Results}

The sensory scores for all spaghetti brands were above 3, an indication of good consumer acceptability. There was no significant $(p>0.05)$ difference among vitAspag, Local, Oba and Spaghetti with respect to all sensory attributes considered. The moisture, ash and fibre content ranged from $8.90 \%-9.50 \%, 1.15 \%-1.20 \%$ and $0.42 \%-0.62 \%$, respectively. Spaghetti, had a significantly higher protein $(2.02 \%$ vs. $0.05 \% ; p<0.001)$ and carbohydrates $(81.0 \% v s .79 .7 \% ; p=0.024)$ content compared with VitAspag. VitAspag, was also significantly $(p<0.001)$ higher in $\beta$-carotene, almost 1.6 times higher than Spaghetti. A $125 \mathrm{~g}$ and $500 \mathrm{~g}$ of vitAspag per day will respectively meet $10 \%$ and $9.03 \%$ of the daily vitamin A requirement of children $<5$ years (300 $\mu \mathrm{g}$ RAE/day) and pregnant and lactating mothers $(1,300 \mu \mathrm{g}$ RAE/day).

\section{Conclusion}

Ranking VitAspag similar to the existing commercial brand is an indication that consumers will equally accept it. OFSP puree could be composited with wheat flour up to (48:52\%) on as is basis to make spaghetti and will contribute to a significant amount of dietary intake of vitamin A.

Citation: Richard Atinpoore Atuna, Orange-Fleshed Sweet Potato (Ipomoea batatas L (Lam)) Composite Spaghetti has Good Consumer Acceptability and a Significant Source of Dietary Vitamin A. Food Proc Nutr Sci 1(1): 25-30.

(C)2020 The Authors. Published by TRIDHA Scholars. 
http://www.tridhascholars.org | June-2020

\section{KEYWORDS}

Noodle; Sweet potato; Vitamin A, VitAspag

\section{INTRODUCTION}

Hidden hunger, particularly vitamin A deficiency, is a grave public health issue in most developing countries. In Ghana, vitamin A deficiency (VAD) is severe, with almost three fourth of pre-schoolers and one-fifth of expectant mothers are deficient in vitamin A [1]. Inadequate dietary intake of carotenoid-rich foods could partly account for the high prevalence of VAD in the country. This situation has resulted in the search for more sustainable actions to ameliorate the menace [2]. Food-based approaches such as fortification and biofortification of food; diet diversification and diet education have shown to be a more sustainable means of addressing VAD [3].

Spaghetti and pasta are ancient foods that could be described as a type of dough extruded or stamped into various shapes for cooking. They are consumed in diverse ways all over the world and it is economical, easy to prepare and have a longer shelf life [4]. Noodle products are usually prepared from amber durum wheat that is processed into semolina and mixed with other ingredients [5]. In recent times, there have been conscious efforts to formulate noodles using non-traditional raw materials mainly to improve its nutritional and functional properties [4] as well as reduce the cost of importation of wheat flour, the main ingredient in noodles making. For instance, fortification and supplementation strategies have been previously employed to improve the vitamin and mineral content of food products [6-8]. However, enrichment of spaghetti with natural raw ingredients has been proposed by Marconi and Messia [4] as a sustainable approach to improving the nutrient profile of spaghetti.

OFSP is a good dietary vitamin A source because it contains significant levels of $\beta$-carotene, a provitamin A [9]. For this reason, OFSP is being promoted in subSaharan Africa as a food-based approach in combating

VAD [10]. OFSP has previously been pureed and composited with wheat flour in the baking of bread that met $21 \%$ of the daily vitamin A requirement for lactating mothers and found to be acceptable by consumers [11]. Incorporation of OFSP puree in spaghetti production would help in product diversification and value addition to OFSP. This would provide rural-poor farmers with an exclusive opportunity to improve on their income generation.

The objective of the study by was to develop OFSP-based composite spaghetti and evaluate its sensory quality. The proximate composition and $\beta$-carotene content of the OFSP-based composite spaghetti was also considered.

\section{MATERIALS AND METHODS}

\section{Source of raw material}

Storage roots of Apomuden (Figure 1a \& Figure 1b) were purchased from a local farmer at the Bontanga irrigation scheme, Kumbungu district, Northern Region. Hard wheat flour and salt were also purchased from the Tamale central market.

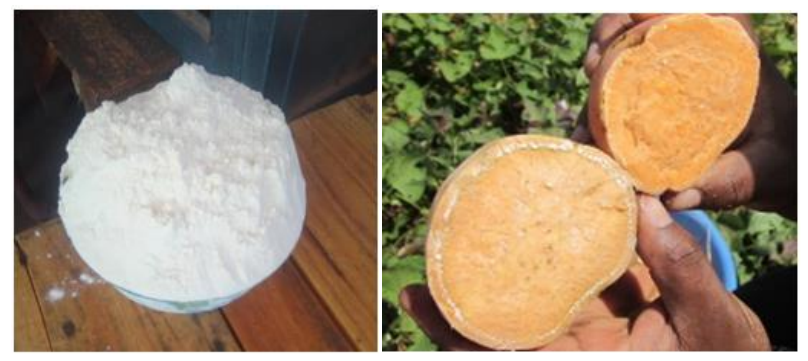

Figure 1: (a) Wheat flour. (b) Apomuden, an orangefleshed sweetpotato variety.

\section{Preparation of OFSP Puree}

Storage roots of about $5 \mathrm{~kg}$ were sorted, washed under running tap water, peeled with a kitchen knife and sliced into a cube and steamed for 35 minutes. The steamed roots were pureed using a Robot Cook (Robot-Cook ${ }^{\circledR}$, 
I5720189101) at a speed of $3000 \mathrm{rpm}$ for 3 minutes. The moisture content of the OFSP puree and wheat flour was $72.8 \% \pm 1.97 \%$ and $10.3 \% \pm 0.24 \%$ respectively.

\section{Processing of Spaghetti}

OFSP puree and wheat flour were mixed at a ratio 48:52 on as is basis and $0.5 \mathrm{~g}$ of iodized salt added to form a mixture. The mixture was then kneaded into a stiff dough and then cut into strands (Figure 2a) using a noodle cutting machine (Marcato Ampia 150, Italy). The strands were dried at room temperature for 24 hours and packaged into flexible polypropylene bags and sealed. Commercial noodles, produced from 100\% wheat flour (Figure 2a Figure 2c), were purchased used as the control.
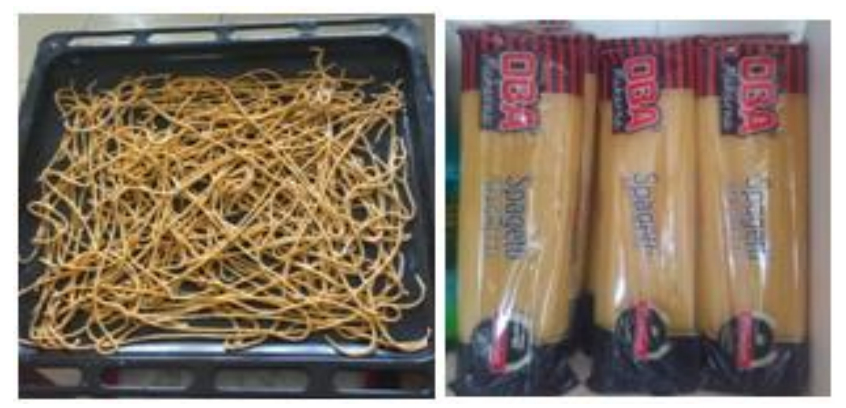

Figure 2: (a) VitAspag. (b) Oba spaghetti.

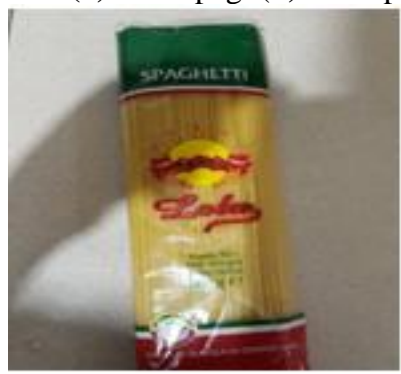

(c) Spaghetti.

\section{Sensory evaluation of cooked spaghetti}

OFSP-based composite noodle was evaluated by 100 untrained panelists, who regularly consume spaghetti. A 5-point hedonic scale (1 - dislike extremely to 5 - like extremely) was used to evaluate the products based on colour, aroma, taste, firmness, stickiness and overall acceptability. Two commercial branded as $\mathrm{Oba}$ and Spaghetti and a non-branded product on the Ghanaian market were included in the consumer testing study.

\section{Proximate composition}

The spaghetti were analyzed, in triplicates using approved methods of the Association of Official Analytical Chemists (AOAC, 1995) for moisture (AOAC 925.10), crude protein (AOAC 960.52), Ash (923.03) and crude fat (AOAC 922.06). Total carbohydrate was estimated by difference.

\section{$\beta$-carotene determination}

The $\beta$-carotene content of VitAspag and spaghetti, one of the commercial noodles in the Ghanaian market was determined using standard methods as described elsewhere [12].

\section{Statistical analysis}

Statistical analysis of the sensory data was performed using Microsoft ${ }^{\circledR}$ Excel 2010/XLSTAT ${ }^{\odot}$-Pro (Version 2016.02, Addinsoft, Inc., Brooklyn, NY, USA). KruskalWallis non-parametric test procedure was employed to analyse the curing treatment. Multiple pair wise comparisons was done using the Steel-Dwass-CritchlowFligner procedure/Two-tailed test when $\mathrm{p}<0.05$. Data on proximate and $\beta$-carotene was subjected to a one-way analysis of variance in Minitab.v16.2.4.4 ${ }^{\mathrm{TM}}$ (Minitab Inc., State College, PA, USA). The Turkey's studentised range test was used to compare differences between means when the ANOVA result was significant $(\mathrm{p}<0.05)$.

\section{RESULTS AND DISCUSSIONS}

There was no significant $(p>0.05)$ difference among the three commercial brands (local, Oba, Spaghetti) and VitASpag in terms of all the sensory properties evaluated (Figure 3). The sensory score for all the sensory attributes were $\geq 4$, an indication of good consumer acceptance of the products assessed. The current findings do not support previous works that showed spaghetti made from whole wheat flour to be more acceptable to consumers compared to made from composite flours of sweetpotato, yam, cocoyam, plantain and cassava [13]. It is worth noting that sweetpotato puree was used in this current study as 
opposed to flour in the previous study, and this may be attributed to the difference in findings. Although not significant, consumers rated the colour for VitAspag higher than the commercially available brands (Local, Oba and Spaghetti). The characteristic yellow colour of VitAspag could account for this higher consumer preference. Colour is an important quality index in spaghetti which impacts purchasing decisions [14]. Martinez, Ribotta, Leon, and Anon [15] reported that among other sensory attributes, yellow colour, can be considered a positive attribute; and an indication of better spaghetti quality.

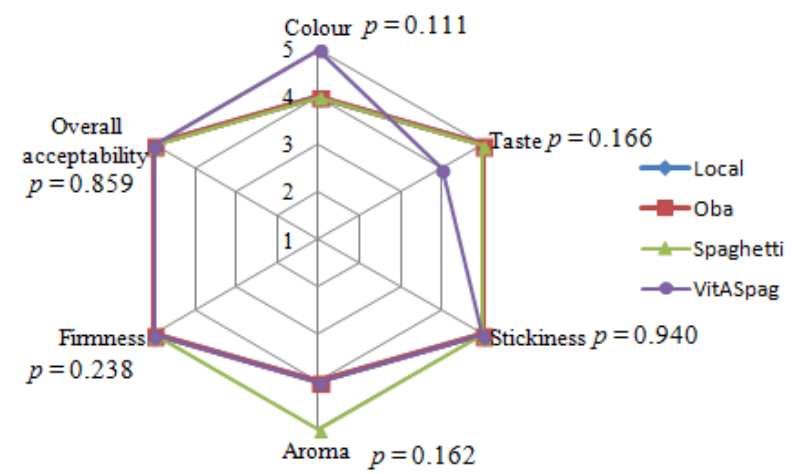

Figure 3: Sensory evaluation of boiled VitAspag and commercial brands.

The compositional data of dry uncooked VitAspag and Spaghetti, one of the commercially available brands in Ghana are presented in Table 1. Generally, there was no significant $(p>0.05)$ difference between VitAspag and Spaghetti in their moisture content. The moisture content of the all brands was lower than the standard of $14 \%$ as required by the codex alimentarius commission for nonfried noodles [16], which could enhance the shelf life of the spaghetti. Low moisture content minimizes the incidence of physical and chemical reactions that may result in product deterioration and lower quality $[17,18]$.

The fat content of VitAspag was significantly ( $p=0.011)$ different; almost 1.6 times higher than Spaghetti, the commercial brand. The data in this study support earlier studies [13] that showed that noodles made with higher substitution levels of sweet potato or plantain flour resulted in increased fat content.

\begin{tabular}{|l|c|c|c|c|c|c|}
\hline \multirow{2}{*}{ Spaghetti Type } & \multicolumn{6}{|c|}{ Proximate Parameters } \\
\cline { 2 - 7 } & Moisture (\%) & Ash (\%) & Fat (\%) & Protein (\%) & Fibre (\%) & Total CH0 (\%) \\
\hline VitASpag & $8.86 \pm 0.453$ & $1.16 \pm 0.213$ & $9.15 \pm 0.285$ & $0.51 \pm 0.025$ & $0.62 \pm 0.295$ & $79.71 \pm 0.630$ \\
\hline Spaghetti & $9.51 \pm 0.769$ & $1.21 \pm 0.306$ & $5.58 \pm 1.347$ & $2.03 \pm 0.045$ & $0.42 \pm 0.195$ & $81.26 \pm 0.423$ \\
\hline p-value & 0.277 & 0.821 & 0.011 & $<0.001$ & 0.383 & 0.024 \\
\hline
\end{tabular}

Table 1: Proximate parameters of VitAspag and Spaghetti on as are basis. Note: Values are means \pm SEM.

The protein content of VitAspag was significantly $(p>0.001)$ different form Spaghetti; almost 4 times lower than the commercial noodle (Table 1). Generally, the protein content of sweetpotato is low ranging from $1.0 \%$ $8.5 \%$ [18] and this could be attributed to the low protein content of VitAspag developed from the partial substitution of OFSP puree. The low protein content suggests that VitAspag may not be a good source of protein unless fortified with protein-rich sources such as legumes. Previous work by Gopalakrishnan, Menon, Padmaja, Sajeev, and Moorthy [19], fortified sweetpotatobased pasta with three protein sources namely: whey protein concentrate, defatted soy flour and fish powder. This was because the protein content of pasta from whole wheat flour or composited contained relatively low protein content.

The total carbohydrate content of commercial brand (Spaghetti) was significantly $(p=0.024)$ higher about $1.6 \%$ more than VitAspag. However, the total carbohydrate content both spaghetti evaluated ranged from 79.71-81.26\%. This indicates that VitAspag could be a good source of carbohydrates. The total carbohydrate content of VitAspag was higher than those reported by Akinsola, Idowu, Laniran, Ojubanire, and Oke [20] for composite sweetpotato-wheat flour spaghetti. However, the total carbohydrate content of VitAspag was similar to the $72 \%-73 \%$ reported for sweetpotato wheat-based noodles. 
The $\beta$-carotene content of dry uncooked VitAspag was compared with one of the commercially available noodles (Spaghetti) and the data is presented in Figure 4.

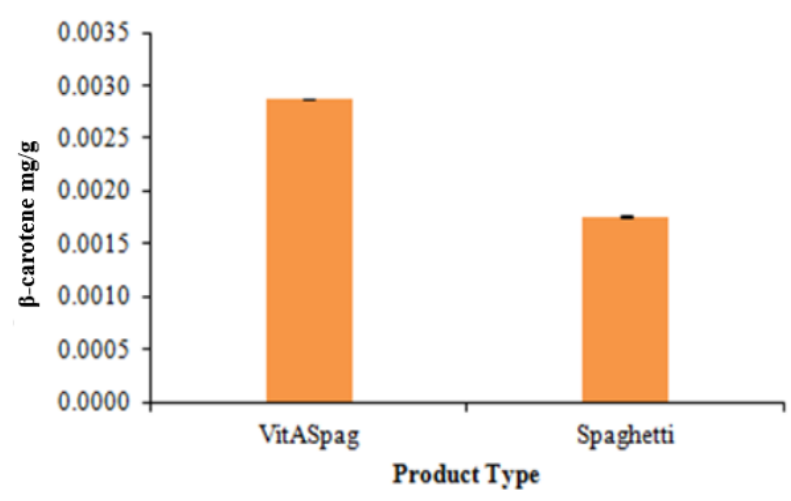

Figure 4: $\beta$-carotene content of VitAspag and Spaghetti. Note: Bars are means $\pm S D$.

VitAspag showed a significantly $(p<0.001 ; 0.0029 v s$. $0.0018 \mathrm{mg} / \mathrm{g}$ ) higher $\beta$-carotene, almost 1.6 times higher than the existing whole-wheat brand, Spaghetti. The partial substitution of wheat flour with $\beta$-carotene-rich OFSP [21] puree led to the higher $\beta$-carotene content in VitAspag compared with the commercial spaghetti. The partial substitution of wheat flour with $48 \%$ OFSP puree in bread making proved to increase the vitamin A content of the bread relative to whole wheat bread [11].

A $125 \mathrm{~g}$ and $500 \mathrm{~g}$ of VitAspag per day will respectively meet $10 \%$ and $9.03 \%$ of the daily vitamin A requirement of children $<5$ years (300 $\mu \mathrm{g}$ RAE/day) and pregnant and lactating mothers $(1,300 \mu \mathrm{g}$ RAE/day).

\section{CONCLUSION}

Spaghetti formulated from $48 \%$ OFSP puree and $52 \%$ wheat flour (VitAspag) had a higher consumer rating as the commercially available spaghetti and this will also contribute significantly to dietary intake of vitamin A. This is an indication that Ghanaian consumers will equally accept VitAspag just as the existing brands in the market as the evaluation was done using panel list familiar with commercially available spaghetti. VitAspag had good nutritional content except that the protein content was relatively lower. The protein content of VitAspag could be improved using protein-rich crops such as soybean.

\section{REFERENCES}

1. World Health Organization (2009) Global prevalence of vitamin A deficiency in populations at risk 1995-2005. WHO global database on Vitamin A deficiency. Geneva, World Health Organization. Geneva, Switzerland: WHO Press.

2. Low JW, Walker T, Hijmans RJ (2001) The potential impact of orange-fleshed sweetpotatoes on vitamin A intake in SubSaharan Africa: 1-16.

3. Berti C, Faber M, Smuts CM (2014) Prevention and control of micronutrient deficiencies in developing countries: Current perspectives. Nutrition and Dietary Supplements 6: 41-57.

4. Marconi E, Messia M (2012) Pasta made from nontraditional raw materials: Technological and nutritional aspects, in durum wheat chemistry and technology, Sissons M, et al. (Eds.) Elsevier BV: St. Paul, Minnesota 55121, USA: 201-211.

5. Adegunwa MO, Bakare HA, Akinola OF (2012) Enrichment of noodles with soy flour and carrot powder. Nigerian Food Journal 30(1): 74-81.

6. Fenech M, Noakes M, Clifton P, et al. (1999) Aleurone flour is a rich source of bioavailable folate in humans. The Journal of Nutrition 129(6): 1114-1119.

7. Seal CJ, Jones AR, Whitney AD (2006) Whole grains uncovered. Nutrition Bulletin 31(2): 129-137.

8. Brennan C (2008) High-fibre pasta products, in Technology of functional cereal products, Hamaker BR (Eds.). Woodhead Publishing limited: Cambridge England: 428-445.

9. Hagenimana V, Low J (2000) Potential of orange-fleshed sweet potatoes for raising vitamin A intake in Africa. Food and Nutrition Bulletin 21(4): 414-418. 
http://www.tridhascholars.org | June-2020

10. Low JW, Arimond M, Osman N, et al. (2007) A food-based approach introducing orange-fleshed sweet potatoes increased vitamin A intake and serum retinol concentrations in young children in rural Mozambique. The Journal of Nutrition 137(5): 1320-1327.

11. Awuni V, Alhassan MW, Amagloh FK (2018) Orange-fleshed sweet potato (Ipomoea batatas) composite bread as a significant source of dietary vitamin A. Food Science \& Nutrition 6(1): 174-179.

12. Biswas AK, Sahoo J, Chatli MK (2011) A simple UV-Vis spectrophotometric method for determination of $\beta$-carotene content in raw carrot, sweet potato and supplemented chicken meat nuggets. LWT-Food Science and Technology 44(8): 1809-1813.

13. Akonor PT, Tortoe C, Buckman ES, et al. (2017) Proximate composition and sensory evaluation of root and tuber composite flour noodles. Cogent Food \& Agriculture 3(1): 1292586.

14. Hatcher DW, Dexter JE, Fu BX (2009) Refrigerated storage of yellow alkaline durum noodles: Impact on color and texture. Cereal chemistry 86(1): 106-112.

15. Martinez CS, Ribotta PD, Leon AE, et al. (2007) Physical, sensory and chemical evaluation of cooked spaghetti. Journal of Texture Studies 38(6): 666-683.

16. Codex Alimentarius Commission (2006) Revised codex standard for instant noodles. Codex Stan: 249.

17. Aguilera J, del Valle J, Karel M (1995) Caking phenomena in amorphous food powders. Trends in Food Science \& Technology 6(5): 149-155.

18. Van Hal M (2000) Quality of sweetpotato flour during processing and storage. Food Reviews International 16(1): 1-37.

19. Gopalakrishnan J, Menon R, Padmaja G, et al. (2011) Nutritional and functional characteristics of protein-fortified pasta from sweet potato. Food and Nutrition Sciences 2(9): 944-955.

20. Akinjide Olubunmi A, Oyeyemi Abraham I, Abigail Mojirade L, et al. (2017) Development, evaluation and sensory quality of orange fleshed sweet potato (Ipomoea batatas Lam) extruded pasta products. Croatian Journal of Food Technology, Biotechnology and Nutrition 12(1-2): 83-89.

21. Tumwegamire S, Mwanga ROM, Andrade M, et al. (2014) Orange-fleshed sweet potato for Africa. Catalogue 2014 (2nd Edn.). International Potato Center (CIP): Lima, Peru: 74. 